\title{
HIV-1 immune activation induces Siglec-1 expression and enhances viral trans-infection in blood and tissue myeloid cells
}

\author{
Maria Pino ${ }^{1}$, Itziar Erkizia', Susana Benet ${ }^{1}$, Elina Eriksonn ${ }^{2,8}$, Maria Teresa Fernández-Figueras ${ }^{3}$, Dolores Guerrero ${ }^{4}$, \\ Judith Dalmau', Dan Ouchi ${ }^{1}$, Antonio Rausell ${ }^{5,6}$, Angela Ciuffi ${ }^{5}$, Oliver T Keppler ${ }^{2}$, Amalio Telenti ${ }^{5,7}$, \\ Hans-Georg Kräusslich ${ }^{8}$, Javier Martinez-Picado ${ }^{1,9,10^{*}}$ and Nuria Izquierdo-Useros ${ }^{1 *}$
}

\begin{abstract}
Background: Myeloid cells are key players in the recognition and response of the host against invading viruses. Paradoxically, upon HIV-1 infection, myeloid cells might also promote viral pathogenesis through trans-infection, a mechanism that promotes HIV-1 transmission to target cells via viral capture and storage. The receptor Siglec-1 (CD169) potently enhances HIV-1 trans-infection and is regulated by immune activating signals present throughout the course of HIV-1 infection, such as interferon a (IFNa).

Results: Here we show that IFNa-activated dendritic cells, monocytes and macrophages have an enhanced ability to capture and trans-infect HIV-1 via Siglec-1 recognition of viral membrane gangliosides. Monocytes from untreated HIV-1-infected individuals trans-infect HIV-1 via Siglec-1, but this capacity diminishes after effective antiretroviral treatment. Furthermore, Siglec-1 is expressed on myeloid cells residing in lymphoid tissues, where it can mediate viral trans-infection.
\end{abstract}

Conclusions: Siglec-1 on myeloid cells could fuel novel CD4 ${ }^{+}$T-cell infections and contribute to HIV-1 dissemination in vivo.

Keywords: Dendritic cells, HIV-1, Trans-infection, Siglec-1

\section{Background}

Antigen presenting cells of the myeloid lineage, such as dendritic cells (DCs), monocytes and macrophages, initiate antiviral immune responses and are crucial to control invading viruses. On the other hand, myeloid cells may also be productively infected with HIV-1 and thus promote pathogenesis. Compared to activated $\mathrm{CD}_{4}^{+} \mathrm{T}$ cells, the permissivity of myeloid cells for HIV-1 is limited [1-3]. This is largely due to restriction by the cellular factor SAMHD1 in these cells $[4,5]$. Nevertheless, myeloid cells can contribute to HIV-1 dissemination through the alternative pathway of trans-infection of $\mathrm{CD}^{+} \mathrm{T}$ cells [6,7]. This mechanism involves HIV-1 capture and uptake by myeloid cells and the subsequent release of trapped viruses at a cell-to-cell

\footnotetext{
* Correspondence: jmpicado@irsicaixa.es; nizquierdo@irsicaixa.es

'AIDS Research Institute IrsiCaixa, Institut d'Investigació en Ciències de la Salut Germans Trias i Pujol IGTP, Universitat Autònoma de Barcelona,

Badalona, Spain

Full list of author information is available at the end of the article
}

contact zone, the infectious synapse, that facilitates infection of $\mathrm{CD} 4^{+} \mathrm{T}$ cells [8].

We and others have previously shown that HIV-1 transinfection requires the sialic acid binding Ig-like lectin 1 (Siglec-1, Sialoadhesin or CD169) [9,10]. Siglec-1 is expressed on the surface of DCs and other myeloid cells $[11,12]$ and recognizes sialyllactose molecules exposed on HIV-1 membrane gangliosides [13,14]. Siglec-1 expression on myeloid cells is induced by activating signals that are present upon acute and chronic immune activation, which is observed in HIV-1-infected patients [15,16]. Various pro-inflammatory factors associated with HIV-1 disease progression stimulate Siglec-1 expression on myeloid cells. Lipopolysaccharide (LPS) is a component of the bacterial cell wall that is significantly increased in 
chronically HIV-1-infected individuals owing to the depletion of gastrointestinal $\mathrm{CD} 4^{+} \mathrm{T}$ cells, which causes systemic translocation of bacteria from the intestinal lumen [17]. In vitro, LPS is able to induce Siglec-1 expression on DCs, potently enhancing their capacity to transinfect HIV-1 [9]. Another factor is interferon alpha (IFN $\alpha$ ) that exerts antiviral effects on HIV-1 replication $[10,18]$, but also serves as a marker of poor clinical prognosis during late-stage disease $[19,20]$. Although IFN $\alpha$ is produced in large quantities by plasmacytoid DCs after HIV-1 challenge $[21,22]$ the key cells responsible for sustained IFN $\alpha$ production in vivo are currently under intensive reexamination $[23,24]$. Regardless of its source, IFN $\alpha$ potently induces the in vitro expression of Siglec-1 on myeloid cells $[10,18]$.

Siglec-1 up-regulation by immune activating signals during HIV-1 infection could play an important role by allowing myeloid trans-infection of multiple target cells. This function could be particularly relevant in lymphoid tissues, the major sites of HIV-1 replication, where myeloid cells migrate and repeatedly establish interactions with $\mathrm{CD}^{+} \mathrm{T}$ cells [25-27], the primary targets of productive HIV-1 infection. In the study described here, we investigated whether Siglec-1 expression on myeloid cells can be induced during chronic HIV-1 infection and thus contribute to systemic viral dissemination. We found that Siglec-1 on myeloid cells is up-regulated in vitro by IFN $\alpha$, allowing for HIV-1 capture and transmission. In vivo, HIV-1 infection enhanced Siglec-1 expression on peripheral blood monocytes, but diminished after effective antiretroviral treatment, reducing the trans-infection capacity of monocytes. Moreover, Siglec1 is present on myeloid cells from lymphoid tissues, where it can mediate HIV-1 trans-infection.

\section{Results}

Siglec-1 mediates HIV-1 capture by IFNa-treated myeloid cells

Siglec-1 expression on the surface of myeloid cells can be stimulated by IFNo $[10,18]$ an antiviral cytokine released by pDCs and possibly by other immune cells after HIV-1 infection $[21,22,24]$. When we compared Siglec-1 expression levels on distinct myeloid cells activated in the presence of IFN $\alpha$, we observed a 17-fold up-regulation in monocytederived DCs and a twofold up-regulation in macrophages and monocytes (Figure 1A).

We have previously reported that Siglec-1 expression levels determine the capacity of DCs to capture HIV-1 [9]. To test whether this also holds true for monocytes and macrophages, we first compared the density of Siglec-1 surface expression applying a quantitative FACS assay that determines the absolute number of Siglec-1 antibody binding sites. This number was highest in IFN $\alpha$-activated monocyte-derived DCs, followed by macrophages and monocytes (Figure 1B). Next, we analyzed binding of infectious HIV-1 to IFN $\alpha$-activated myeloid cells. HIV-1 was incubated with the cells for $4 \mathrm{~h}$ at $4^{\circ} \mathrm{C}$ to avoid viral internalization and cell-associated p24 ${ }^{\text {Gag }}$ was quantified by ELISA after extensive washing. Consistent with their respective Siglec-1 expression levels (Figure 1B), IFNoactivated monocyte-derived DCs showed a higher HIV-1 binding capacity than monocytes (Figure 1C). To investigate whether this binding was specific for Siglec-1, cells were pre-treated with a monoclonal antibody (mAb) against Siglec-1. This treatment led to a reduction of HIV1 binding by $83 \%$ in all cases, while isotype control treatment had no inhibitory effect (Figure 1D). Similar results were obtained with fluorescent HIV-1 Virus-Like Particles (VLPs), which lack the viral envelope glycoprotein but carry sialyllactose-containing gangliosides recognized by Siglec-1 (Additional file 1: Figure S1A-B). These data indicate that Siglec-1 is the main molecule responsible for HIV-1 capture by IFN $\alpha$-activated myeloid cells, and that its expression correlates with the viral binding capacity of the respective cell type.

\section{Siglec-1 mediates HIV-1 uptake into a storage compartment and enhances HIV-1 trans-infection specially in IFNa-treated monocytes and DCs}

Having established Siglec-1-dependent virus binding in all three types of myeloid cells, we performed uptake experiments at $37^{\circ} \mathrm{C}$ to follow the fate of the bound virus. IFN $\alpha$ activated myeloid cells were incubated with HIV-1 for $4 \mathrm{~h}$ at $37^{\circ} \mathrm{C}$ and cell-associated p24 ${ }^{\mathrm{Gag}}$ was quantified by ELISA after extensive washing (Figure 2A). Monocyte-derived DCs and monocytes contained similar amounts of HIV-1, while macrophages displayed lower uptake (Figure 2A). Treatment with Bafilomycin A1, an inhibitor of lysosomic degradation, only increased the level of cell-associated virus in macrophages (Figure 2B). Thus, faster viral degradation in macrophages accounts for the reduced cell-associated virus observed in this cell type (Figure 2A). HIV-1 uptake was strongly inhibited by a $\mathrm{mAb}$ against Siglec-1 in all cases (Figure 2C). Similar results were obtained when we performed uptake experiments with fluorescent VLPs (Additional file 1: Figure S1C-D), with macrophages showing residual capture in the presence of the mAb (Additional file 1: Figure S1D).

To elucidate the HIV-1 trafficking differences in macrophages compared to other myeloid cells, we investigated viral uptake by confocal microscopy. IFN $\alpha$-treated myeloid cells were pulsed with fluorescent HIV-1 $1_{\text {Cherry }}$ for $4 \mathrm{~h}$ at $37^{\circ} \mathrm{C}$ and subsequently stained with $\mathrm{mAbs}$ against Siglec- 1 and against HLA-DR to reveal cellular membranes (Figure 2D, top images). While most of the monocyte-derived DCs and monocytes accumulated HIV-1 $1_{\text {Cherry }}$ within a sac-like compartment enriched in Siglec-1, macrophages exhibited a more scattered 


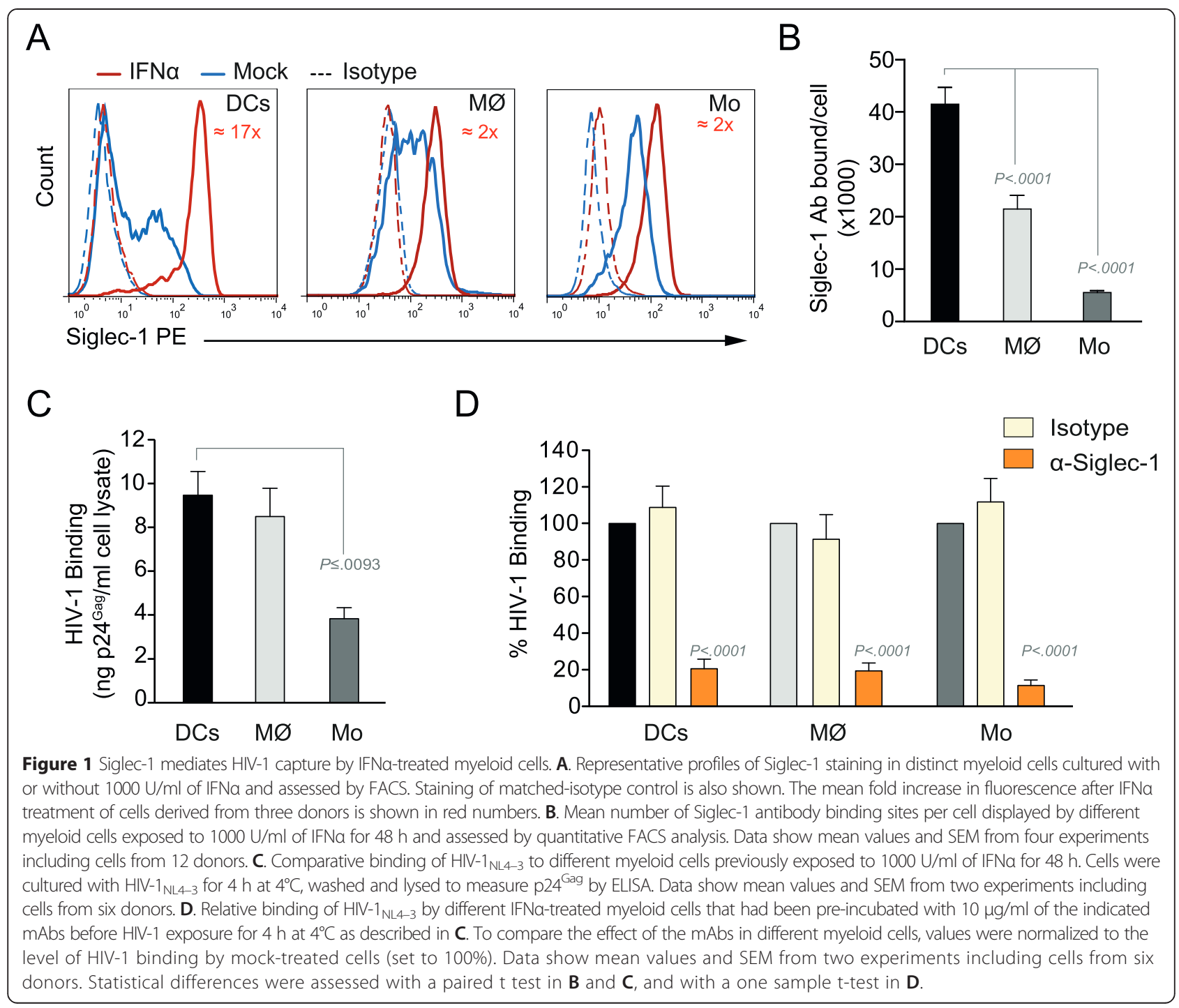

pattern for cell-associated HIV-1 $1_{\text {Cherry }}$ (Figure 2D). Thus, the complementary approaches of confocal microscopy analysis and viral uptake experiments indicate that Siglec-1 is essential for HIV-1 capture in all myeloid cells, while it is not sufficient for further downstream uptake and trafficking involved in the formation of a condensed viral compartment.

We next assessed the capacity for HIV-1 trans-infection by the different myeloid cell types. Cells were pulsed with equal amounts of the X4-tropic HIV- $1_{\mathrm{NL} 4-3}$ followed by extensive washing and were subsequently co-cultured with a $\mathrm{CD} 4^{+}$reporter cell line for two days. Monocyte-derived DCs had the highest capacity for trans-infection followed by monocytes, while macrophages showed only weak trans-infection capacity (Figure 2E), consistent with their faster viral degradation kinetics (Figure 2B). However, trans-infection depended on Siglec-1 in all cases (Figure 2F).
Siglec-1 is up-regulated on monocytes from HIV-1-infected individuals, and its expression is reduced upon successful antiretroviral treatment

To explore whether Siglec-1 could be functionally important in vivo, we assessed Siglec-1 expression on blood monocytes from HIV-1-infected individuals before and after initiation of antiretroviral treatment (Table 1), and compared them to HIV-1-negative individuals. When we quantified the number of Siglec-1 Ab binding sites per monocyte ex vivo we found that Siglec-1 expression was significantly lower in HIV-1-negative individuals compared to untreated HIV-1-infected individuals (Figure 3A; 6 -fold difference, $P=0.0006)$. Furthermore, Siglec-1 expression was significantly higher in monocytes isolated before antiretroviral treatment compared to monocytes isolated after antiretroviral treatment from the same patients (Figure 3A; 7-fold difference, $P=0.0017$ ), returning to the levels showed by HIV-1-negative individuals. 


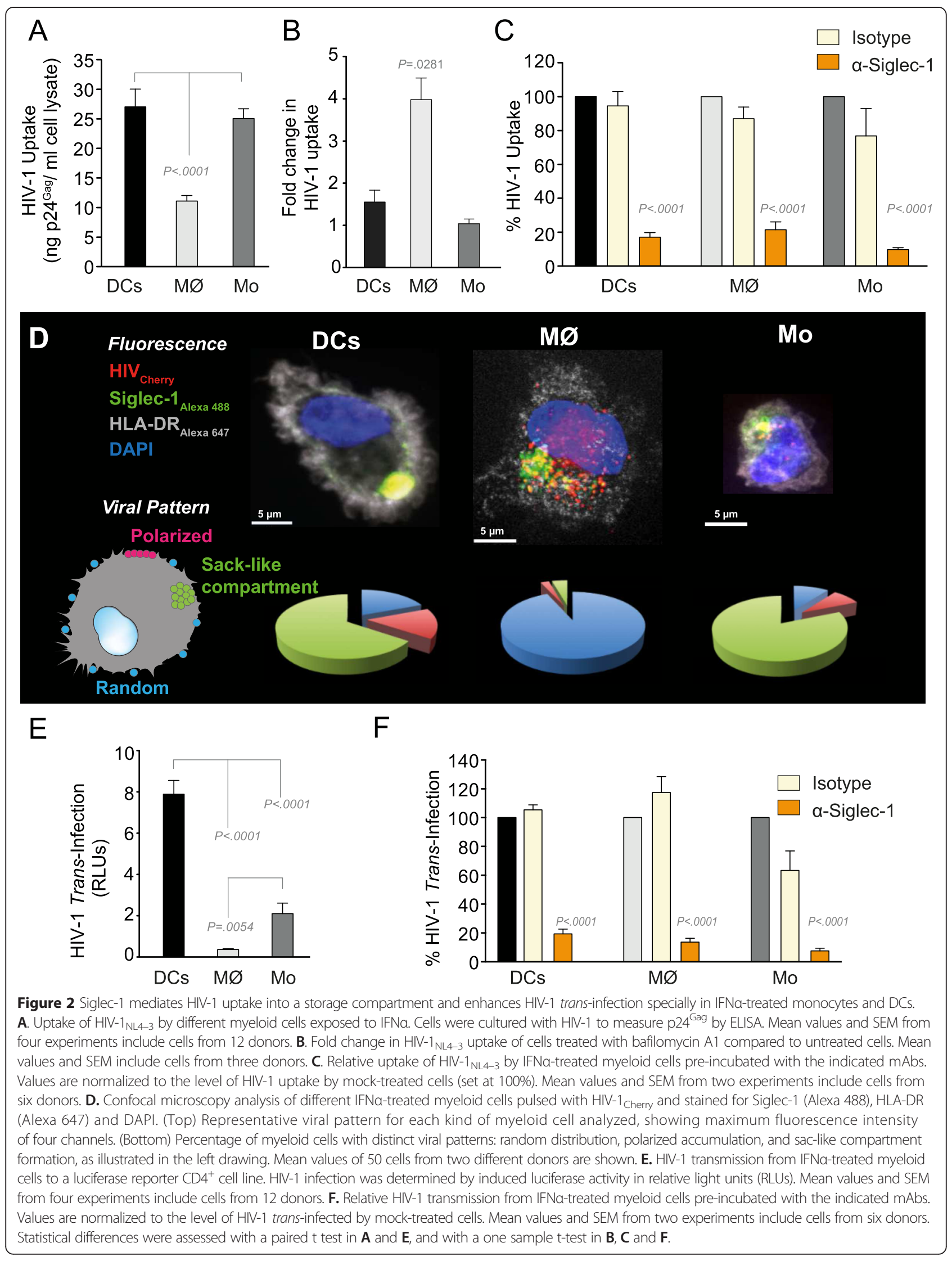


Table 1 Characteristics of the HIV-1-infected men followed longitudinally before and after initiation of antiretroviral treatment that are shown in Figures 3 and 4

\begin{tabular}{|c|c|}
\hline PRE/POST Antiretroviral treatment & Number or Median (IQR) \\
\hline Number of patients & 16 \\
\hline Age (years) & $36(24-40)$ \\
\hline \multicolumn{2}{|l|}{ Antiretroviral treatment regimen } \\
\hline $\begin{array}{l}\text { Non-Nucleoside Reverse Transcriptase } \\
\text { Inhibitors }\end{array}$ & 8 \\
\hline Protease Inhibitors & 7 \\
\hline Integrase Inhibitors & 1 \\
\hline $\begin{array}{l}\text { Time from diagnosis to antiretroviral } \\
\text { treatment (months) }\end{array}$ & $2(1.5-5)$ \\
\hline Time between samples (months) & $11(7-19)$ \\
\hline \multicolumn{2}{|l|}{$\mathrm{CD}^{+}{ }^{+}$-cell count (cells/ $\left.\mu \mathrm{l}\right)$} \\
\hline PRE antiretroviral treatment & $297(239-316)$ \\
\hline POST antiretroviral treatment & $505(401-597)$ \\
\hline \multicolumn{2}{|l|}{$\begin{array}{l}\text { Plasma Viral Load ( } \log _{10} \text { HIV RNA } \\
\text { copies } / \mathrm{ml} \text { ) }\end{array}$} \\
\hline PRE antiretroviral treatment & $5(4.4-5.5)$ \\
\hline POST antiretroviral treatment & $1.7(1.4-1.7)$ \\
\hline
\end{tabular}

Next, we compared monocytes from HIV-1-infected individuals for their capacity to take up VLPs. Consistent with their higher expression of Siglec-1, cells isolated before antiretroviral treatment exhibited a higher uptake capacity for VLPs compared to cells obtained under suppressive therapy (Figure 3B; 19-fold difference, $P=0.0039$ ). Similar results were observed for uptake of complete HIV-1 (Figure 3C). Consistent with the enhanced uptake, HIV-1 trans-infection was also higher for cells taken before antiretroviral treatment (Figure 3D, $P=0.0117$ ). These results indicate that in vivo, Siglec-1 expression on peripheral blood monocytes is up-regulated by HIV-1 infection, but normalizes after effective antiretroviral treatment suppresses viral replication and the associated immune activation $[17,28]$.

\section{The plasma of untreated HIV-1-infected individuals stimulates Siglec- 1 expression and signals via the type I IFN receptor}

To assess if immune activating factors present in the plasma could trigger Siglec-1 expression on myeloid cells, we tested the capacity of such plasma to induce Siglec-1 expression on DCs derived from uninfected donors. When we quantified the number of Siglec-1 Ab binding sites per DC, we found that plasma from untreated HIV-1-infected individuals triggered Siglec-1 expression to a higher extent than plasma from HIV-1-negative individuals (Figure 4A). Induction of Siglec-1 expression was reduced to the level

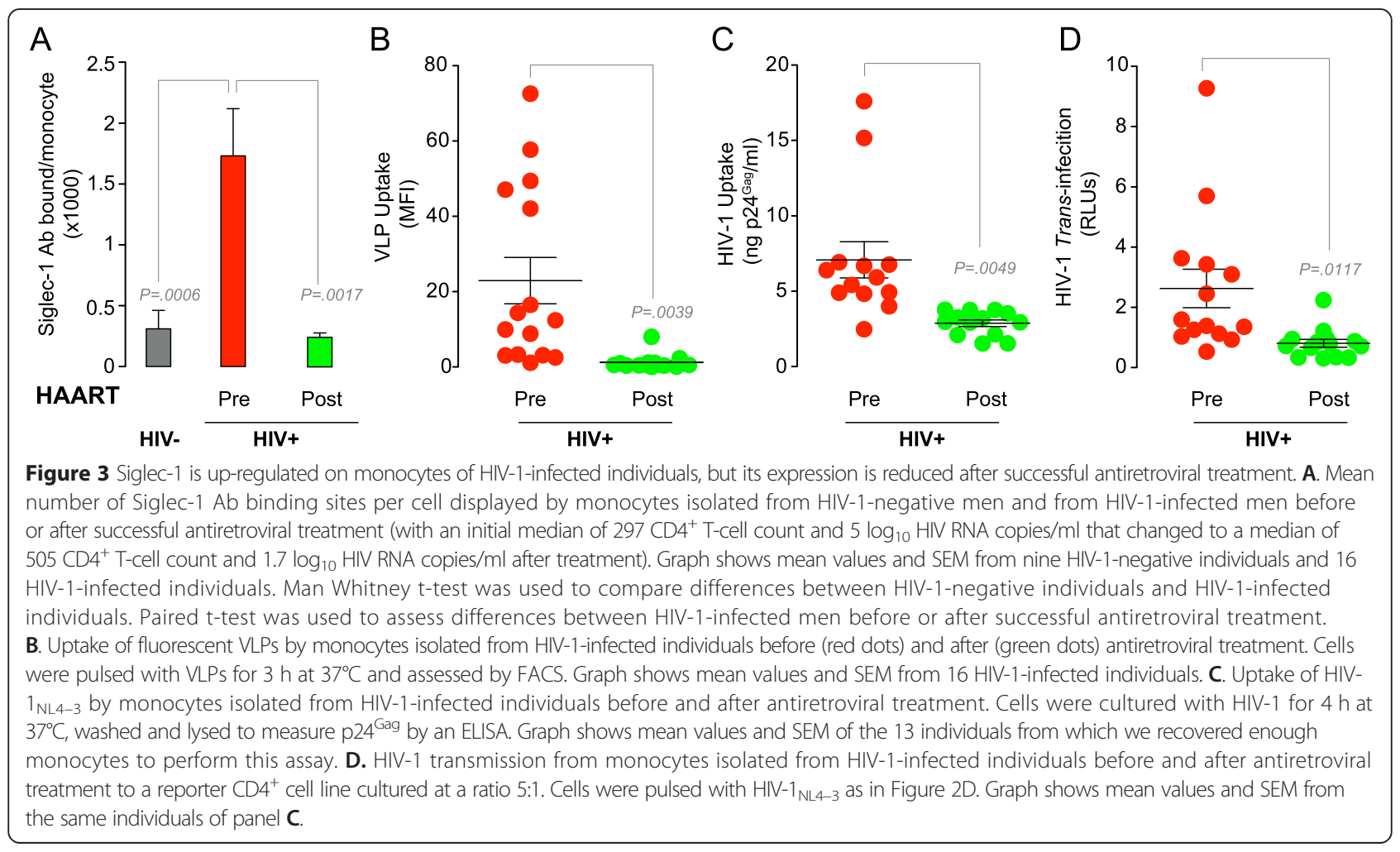



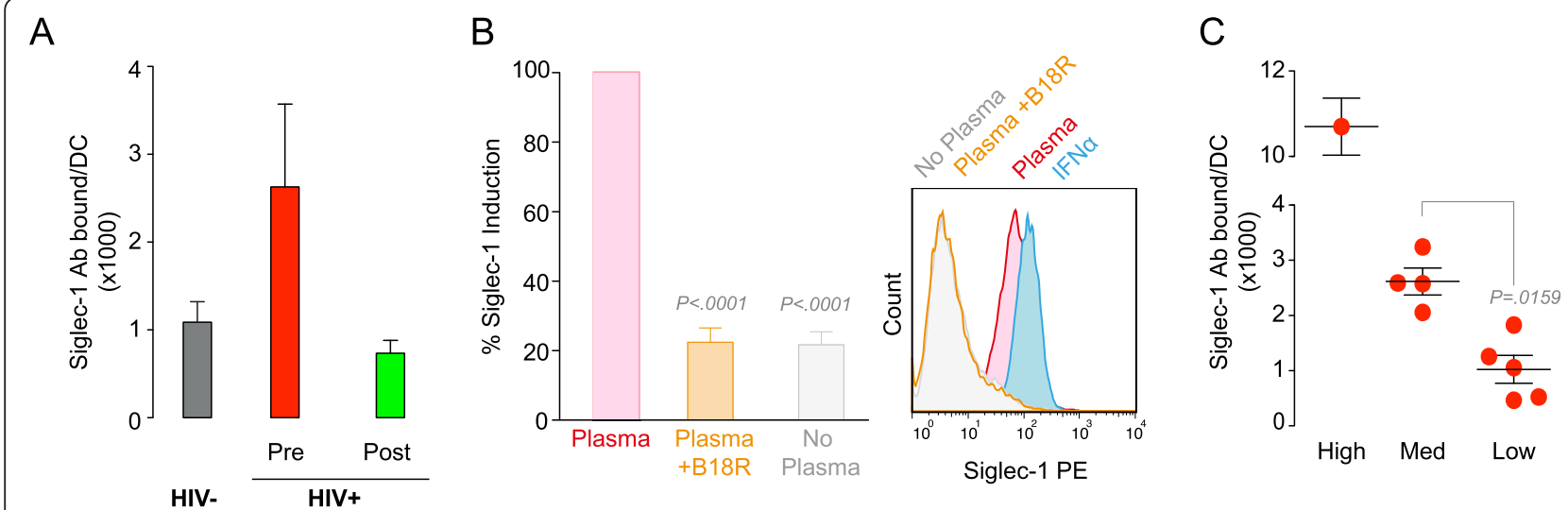

Figure 4 The plasma of untreated HIV-1-infected individuals stimulates Siglec-1 expression and signals via type I IFN receptor. A. Mean number of Siglec-1 Ab binding sites per cell induced by the plasma of HIV-1-negative individuals and HIV-1-infected individuals before or after successful antiretroviral treatment, respectively. DCs derived from uninfected donors were cultured for $24 \mathrm{~h}$ in the presence of plasma and then stained for Siglec-1. Graph shows mean values and SEM of Siglec-1 induction in DCs from two donors that were tested in parallel with the plasmas from five HIV-1-negative individuals and ten HIV-1-infected individuals. B. Relative blockade of Siglec-1 expression by B18R, a soluble recombinant receptor with high affinity for type I IFNs, which inhibits Siglec-1 induction triggered by the plasmas of untreated HIV-1-infected individuals. DCs were cultured for $24 \mathrm{~h}$ with the respective plasma in the presence or absence of $2 \mu \mathrm{g} / \mathrm{ml}$ of B18R. Values are normalized to the level of Siglec-1 induction by plasma of mock-treated cells (set at 100\%). Mean changes from 100\% were assessed with a one sample t-test. Representative histogram also depicts IFNa-treated DCs. C. Mean number of Siglec-1 Ab binding sites per cell induced by the plasma of untreated HIV-1-infected individuals. DCs were cultured for $24 \mathrm{~h}$ in the presence of plasma collected from patients displaying the highest levels of Siglec-1 (>5500 Ab binding sites per monocyte), intermediate levels of Siglec-1 (4000-2500 Ab binding sites per monocyte) or the lowest levels of Siglec-1 (<1500 Ab binding sites per monocyte) and then stained for Siglec-1. Graph shows mean values and SEM of Siglec-1 induction in DCs from two donors that were tested in parallel with the plasmas from ten HIV-1-infected individuals. Man Whitney t-test was used to compare the differences between distinct plasmas to induce Siglec-1 expression.

triggered by plasma from uninfected individuals when plasma from the same HIV-1-infected individuals but isolated after antiretroviral treatment was used (Figure 4A). This effect was mediated by signaling through the type I IFN receptor, since B18R, a soluble recombinant receptor with high affinity for type I IFNs, blocked Siglec-1 induction triggered by plasma from untreated HIV-1-infected patients (Figure 4B). Furthermore, addition of IFN $\alpha$ up-regulated Siglec-1 expression to similar levels as the plasma from untreated HIV-1-infected patients (Figure 4B). Moreover, plasma from those untreated HIV-1-infected individuals that displayed the highest level of Siglec-1 Ab binding sites per monocyte in peripheral blood was able to trigger Siglec-1 expression in donor DCs to a higher extent than plasma from individuals exhibiting lower levels of Siglec-1 (Figure 4C). Thus, the capacity to induce Siglec-1 via soluble factors in the plasma of HIV-1-infected individuals is related to Siglec-1 levels on the surface of monocytes from the respective donor, indicating that Siglec-1 expression in vivo is indeed regulated by soluble activation factors signaling via the type I IFN receptor.

\section{Expression of Siglec-1 on monocytes correlates with clinical parameters}

Focusing our analysis on antiretroviral treatment-naive patients (Table 2), we found a positive correlation between Siglec-1 expression levels on isolated monocytes and i) VLP uptake (Figure 5A; $\rho=0.8924 ; P<0.0001$ ), ii) HIV-1 uptake
(Figure 5B; $\rho=0.8069 ; P=0.0009)$, and iii) HIV-1 transinfection capacity (Figure $5 C ; \rho=0.7833 ; P=0.0015$ ). In addition, Siglec-1 expression levels positively correlated with plasma viral load (Figure 5D; $\rho=0.6673 ; P=0.0002$ ). Conversely, Siglec-1 expression negatively correlated with CD4 ${ }^{+}$T-cell counts (Figure $5 E ; \rho=-0.5236 ; P=0.006$ ).

\section{Siglec-1 positive cells accumulate in inflamed lymphoid tissues in areas enriched in $\mathrm{CD}^{+} \mathrm{T}$ cells}

To establish whether Siglec-1 can be detected in lymphoid tissues where myeloid cells establish continuous cell-to-cell interactions that could favor viral transmission, we first performed immunohistochemical analyses of tissues from HIV-1 uninfected individuals. Sections from paraffin-embedded tonsils derived from HIV-, HBVand $\mathrm{HCV}$-negative patients were classified as inflamed $(n=3)$ or non-inflamed $(n=3)$ based on histopathological criteria. Inflamed tonsils harbored on average 23-fold more Siglec-1-positive cells than non-inflamed tonsils (Figure 6A), indicating a clear association between the degree of immune activation and the number of cells expressing the trans-infection receptor.

We next assessed whether Siglec-1 expressing cells could be detected in lymphoid tissue from an HIV-1-infected individual who had lymph nodes removed before and after initiation of antiretroviral treatment. Of note, this patient also had an untreated HCV infection. Siglec-1 positive cells were detected in perivascular, sub-capsular, and 
Table 2 Characteristics of the HIV-1-infected men before initiation of antiretroviral treatment, whose samples were used in Figure 5

\begin{tabular}{ll}
\hline PRE Antiretroviral treatment & Number or Median (IQR) \\
\hline Number of patients & 26 \\
Age (years) & $36(24-40)$ \\
CD4 ${ }^{+}$T-cell count (cells/Ml) & $338.5(285-721)$ \\
Plasma Viral Load (Log 10 HIV & $4.3(2.9-5.3)$ \\
RNA copies/ml) & \\
\hline
\end{tabular}

perifollicular areas enriched in $\mathrm{CD} 4^{+} \mathrm{T}$ cells, but mostly excluded from CD20-positive follicular zones (Figure 6B). A similar pattern was observed for tissue obtained before and after initiation of therapy. Although we cannot rule out the possibility that untreated $\mathrm{HCV}$ infection sustained Siglec-1 expression, it is also conceivable that antiretroviral drug concentrations were insufficient to fully suppress HIV-1 replication in the lymphoid tissue of this particular individual $[29,30]$ thus sustaining IFN $\alpha$ production.

\section{Siglec-1 mediates HIV-1 trans-infection by myeloid cells isolated from lymphoid tissue}

Detection of Siglec-1 on cells residing in lymphoid tissues prompted us to further characterize the role of tonsilderived Siglec-1 positive cells in HIV-1 capture and transinfection ex vivo. Cells were isolated from non-inflamed tonsils of HIV-1-uninfected individuals as depicted in Figure 7A. After mechanical disruption, mononuclear tonsillar cells were isolated by Ficoll-Hypaque gradient centrifugation. T- and B-lymphocytes were subsequently depleted with magnetic beads and the remaining cell fraction was cultured in the presence of IFNa or left untreated. FACS analysis revealed an up-regulation of Siglec-1 after $24 \mathrm{~h}$ of IFN $\alpha$ treatment.

We next isolated Siglec-1 positive cells by sorting of IFN $\alpha$ treated tonsillar cells and performed a full transcriptome

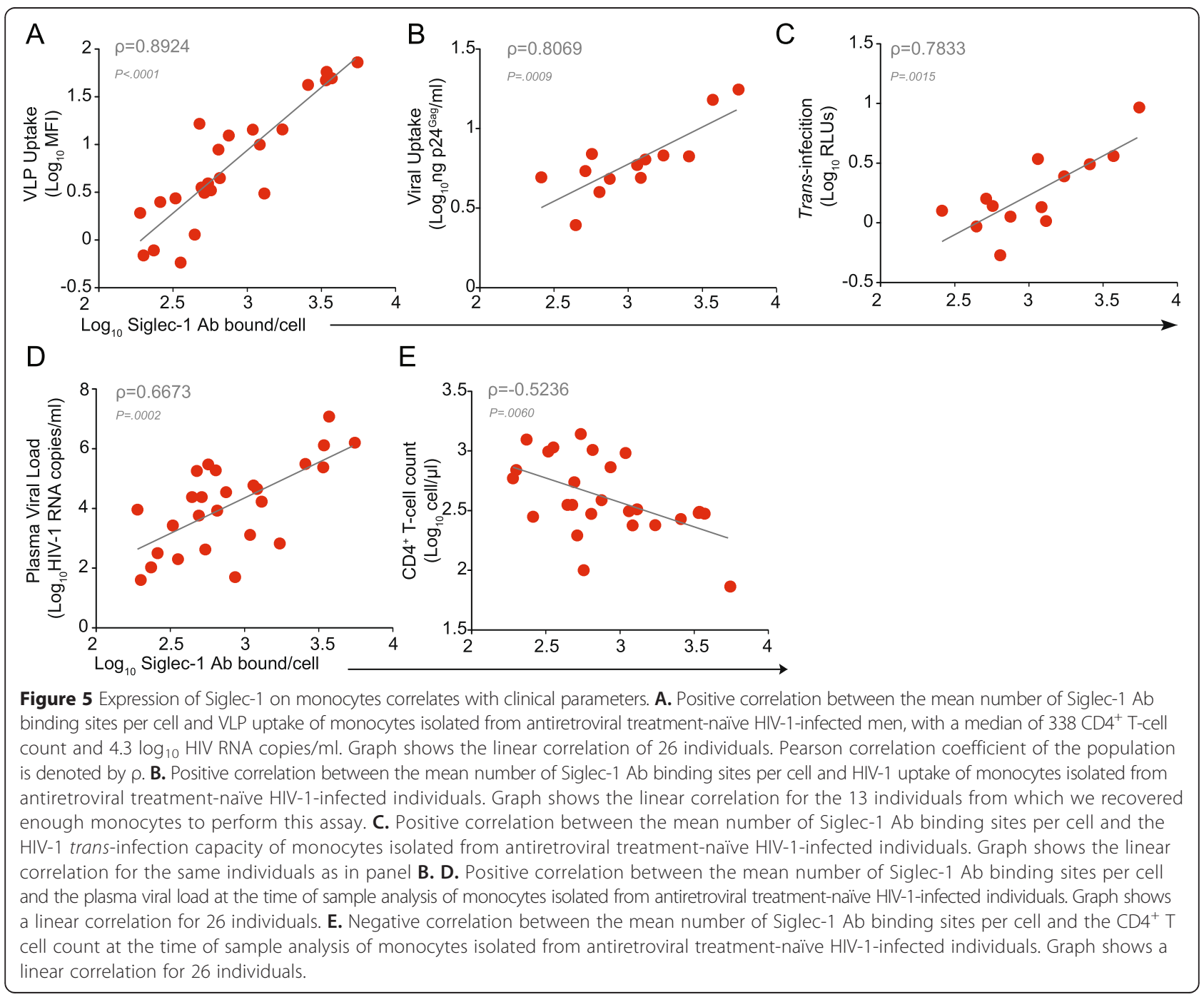




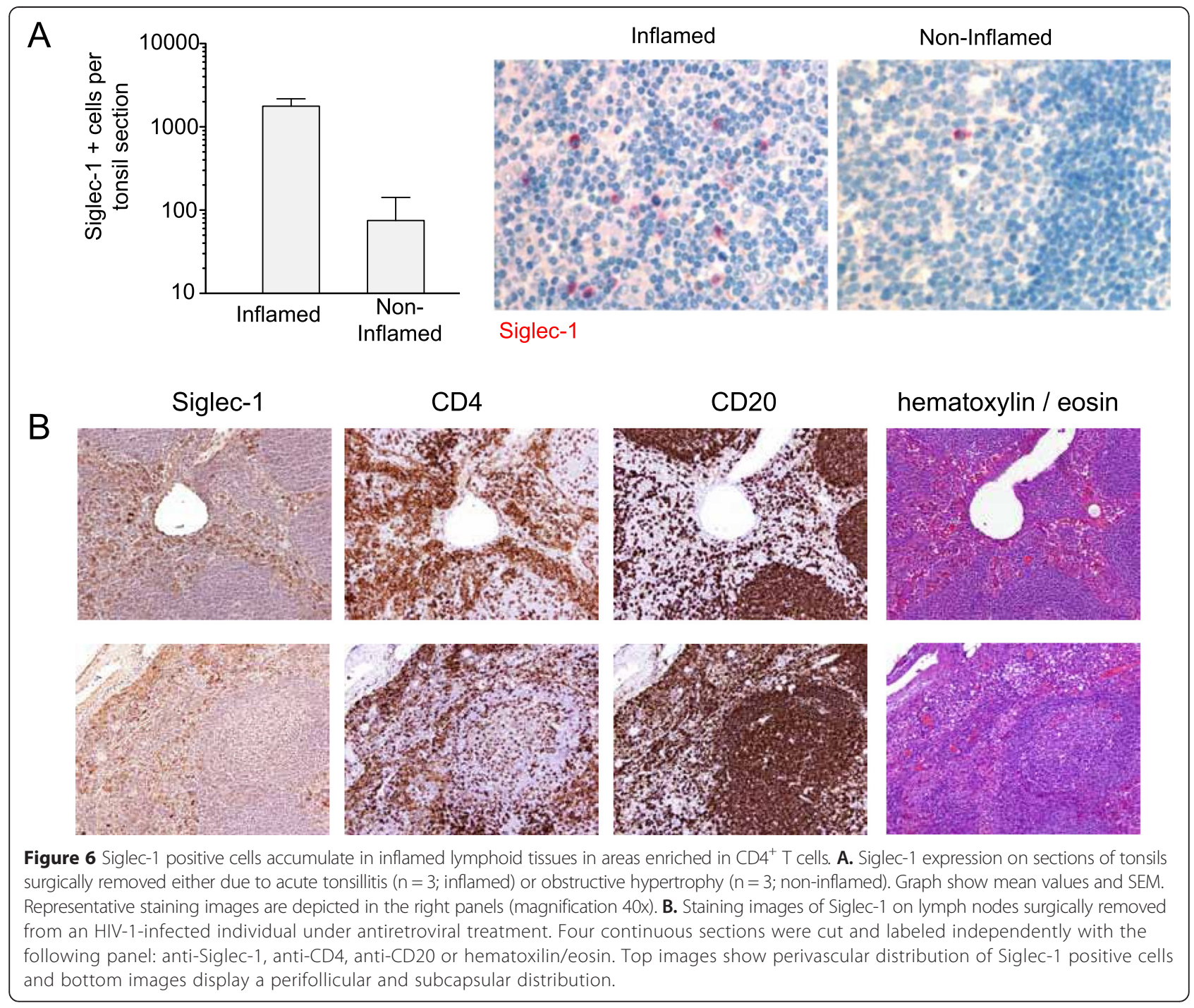

RNA-seq analysis. Results were compared to a similar RNA-seq analysis of the previous IFN $\alpha$-treated myeloid cells (DCs, macrophages and monocytes), and also to $\mathrm{CD}^{+}{ }^{+} \mathrm{T}$ cells exposed to IFN $\alpha$. Hierarchical clustering of samples on the basis of their protein coding gene expression levels revealed that sorted Siglec-1 positive tonsillar cells clustered closer to the other myeloid cells and away from CD4 $4^{+} \mathrm{T}$ cells (Figure 7B). Sorted Siglec-1 positive cells shared almost 6000 protein coding genes with other myeloid cells (expressed more than 100 library size-normalized reads per kilobase of exonic sequence, Figure $7 \mathrm{C}$ ), among which we found a significant enrichment of genes related to antigen-presenting functions (Table 3). Analysis of transcript levels of genes related to antigen-presenting functions revealed heterogeneous gene expression levels across individual myeloid cells and tonsil-derived Siglec-1 positive cells (Figure 7D). Siglec-1 was highly expressed in all cell types (more than 2,000 library size-normalized reads per kilobase of exonic sequence). Specific markers of tissue origin, such as CCR7 and CCL19, were found overexpressed in tonsil-derived Siglec-1 positive cells (Figure 7D). When we plotted a heat map-like representation based on a panel of markers recently proposed for identifying different human mononuclear phagocyte subsets [31] tonsilderived Siglec-1 positive cells expressed most of those markers, but showed a distinctive profile (Figure 7E). Siglec-1 positive tonsillar cells expressed CD1c (BDCA1), CD1a and CD14 (Figure 7E), which are all markers found in other primary human myeloid cells isolated from inflammatory fluids [32]. Thus, the unique pattern of tonsilderived Siglec-1 positive cells might reflect the complexity of classifying mononuclear phagocytes under inflammatory conditions [31]. Overall, transcriptomic analysis indicated that sorted Siglec-1 tonsillar cells presented a unique myeloid antigen-presenting cell profile.

After GO enrichment analysis, 507 GO processes were found significantly enriched, where most of the genes (3564) were related to cellular metabolic processes (GO:0044237). 


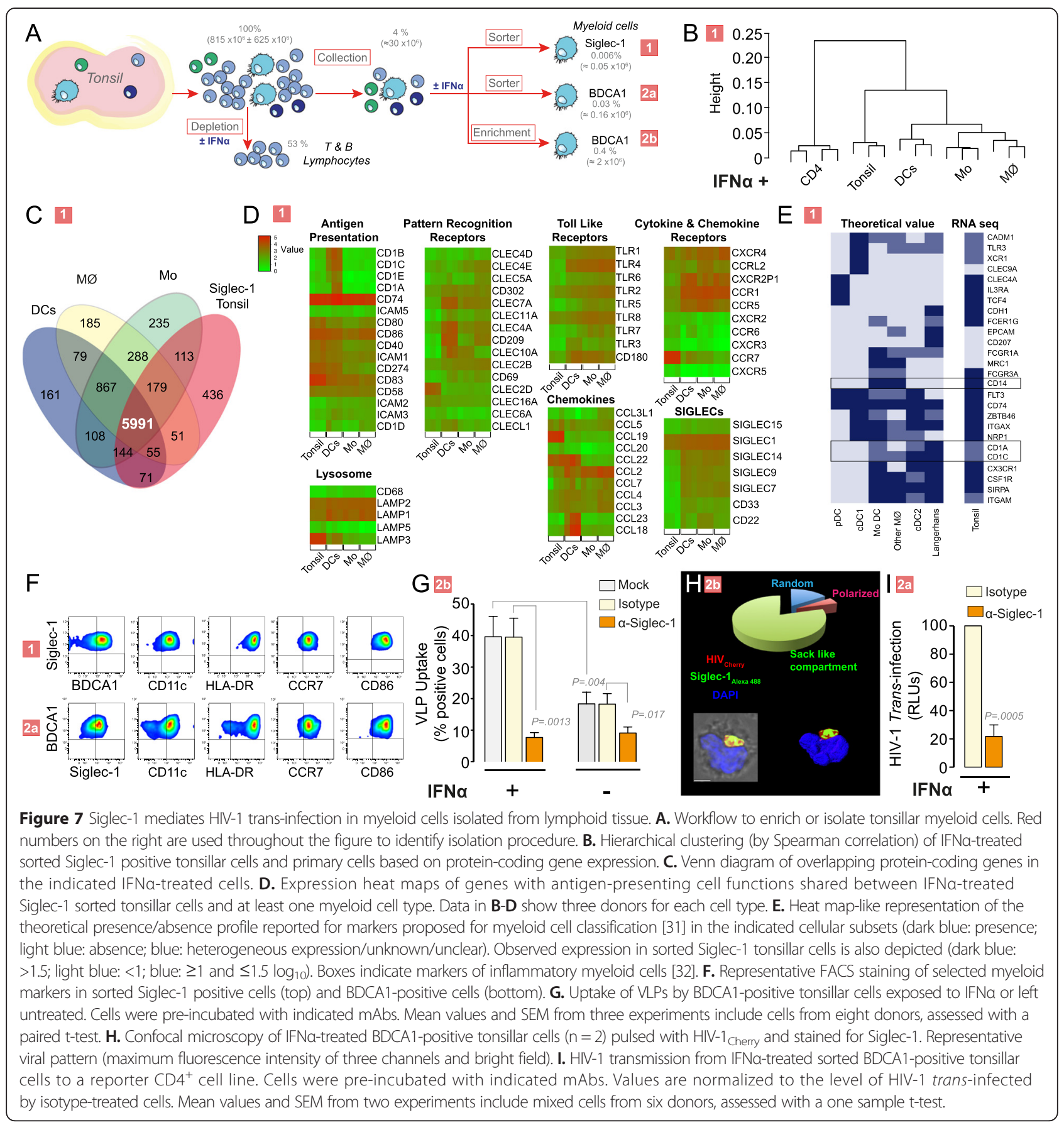

Here we just summarize the enriched GO processes related to immune function, the number of genes categorized in each GO function, the actual number of genes found in the 5991 protein coding genes commonly expressed, the expected $P$ value and the real $P$ value obtained for the genes of interest.

Sorted Siglec-1 positive cells from IFN $\alpha$-treated tonsils co-stained with several myeloid markers that had been identified in the transcriptomic analysis, including BDCA1, CD11c, HLA-DR, CCR7 and CD86
(Figure 7F, top panels). However, sorted Siglec-1 positive cells could not be employed in functional assays, since mAbs against Siglec-1 block HIV-1 capture (Figure 1D). When we sorted BDCA1-positive cells from IFN $\alpha$-treated tonsillar cells, they also stained positive for Siglec-1, CD11c, HLA-DR, CCR7 and CD86 (Figure 7F, bottom panels), indicating that this population had a comparable phenotype to that exhibited by Siglec-1 positive cells and could be used for functional assays. 
Table 3 List of GO biological processes relevant for antigen-presenting cell function found significantly enriched after Bonferroni correction in the 5991 protein coding genes commonly expressed by sorted tonsil-derived Siglec-1 positive cells and the different types of myeloid cells exposed to IFNa

\begin{tabular}{|c|c|c|c|c|}
\hline GO biological process & Genes in GO process & Genes found & Expected & P-value \\
\hline Immune system process (GO:0002376) & 1875 & 791 & $5,10 E+05$ & $1,38 \mathrm{E}-27$ \\
\hline Regulation of immune system process (GO:0002682) & 1090 & 439 & $2,96 \mathrm{E}+05$ & $3,63 \mathrm{E}-09$ \\
\hline Positive regulation of immune system process (GO:0002684) & 636 & 273 & $1,73 E+05$ & $2,06 \mathrm{E}-06$ \\
\hline Defense response (GO:0006952) & 1256 & 490 & $3,42 \mathrm{E}+05$ & $1,30 \mathrm{E}-08$ \\
\hline Regulation of defense response (GO:0031347) & 502 & 218 & $1,37 E+05$ & $1,69 \mathrm{E}-04$ \\
\hline Immune response (GO:0006955) & 1153 & 476 & $3,14 \mathrm{E}+05$ & $3,06 \mathrm{E}-12$ \\
\hline Regulation of immune response (GO:0050776) & 712 & 303 & $1,94 \mathrm{E}+05$ & $2,89 \mathrm{E}-07$ \\
\hline Positive regulation of immune response (GO:0050778) & 428 & 200 & $1,16 \mathrm{E}+05$ & $2,52 \mathrm{E}-06$ \\
\hline Activation of immune response (GO:0002253) & 344 & 175 & $9,35 E+04$ & $7,68 \mathrm{E}-08$ \\
\hline Immune response-activating signal transduction (GO:0002757) & 296 & 165 & $8,05 E+04$ & $2,15 \mathrm{E}-10$ \\
\hline Immune response-regulating signaling pathway (GO:0002764) & 403 & 202 & $1,10 E+05$ & $3,18 \mathrm{E}-09$ \\
\hline Immune effector process (GO:0002252) & 399 & 194 & $1,09 \mathrm{E}+05$ & $1,82 \mathrm{E}-07$ \\
\hline Response to virus (GO:0009615) & 250 & 129 & $6,80 \mathrm{E}+04$ & $7,85 \mathrm{E}-05$ \\
\hline Innate immune response (GO:0045087) & 773 & 362 & $2,10 E+05$ & $6,72 \mathrm{E}-16$ \\
\hline Regulation of innate immune response (GO:0045088) & 246 & 141 & $6,69 \mathrm{E}+04$ & $4,76 \mathrm{E}-09$ \\
\hline Positive regulation of innate immune response (GO:0045089) & 178 & 106 & $4,84 \mathrm{E}+04$ & $1,63 \mathrm{E}-06$ \\
\hline Activation of innate immune response (GO:0002218) & 148 & 94 & $4,02 \mathrm{E}+04$ & $1,04 \mathrm{E}-06$ \\
\hline Innate immune response-activating signal transduction (GO:0002758) & 141 & 91 & $3,83 E+04$ & $1,05 E-06$ \\
\hline Antigen processing and presentation (GO:0019882) & 222 & 142 & $6,04 \mathrm{E}+04$ & $5,93 \mathrm{E}-13$ \\
\hline Of peptide antigen (GO:0048002) & 186 & 126 & $5,06 \mathrm{E}+04$ & $8,41 \mathrm{E}-13$ \\
\hline Of peptide antigen via MHC class I (GO:0002474) & 101 & 81 & $2,75 E+04$ & $3,02 \mathrm{E}-10$ \\
\hline Of exogenous antigen (GO:0019884) & 172 & 119 & $4,68 \mathrm{E}+04$ & $1,77 \mathrm{E}-12$ \\
\hline Of exogenous peptide antigen (GO:0002478) & 170 & 117 & $4,62 E+04$ & $5,08 \mathrm{E}-12$ \\
\hline Of exogenous peptide antigen via MHC class I (GO:0042590) & 79 & 64 & $2,15 E+04$ & $3,07 \mathrm{E}-07$ \\
\hline Of exogenous peptide antigen via MHC class I, TAP-dependent (GO:0002479) & 75 & 61 & $2,04 \mathrm{E}+04$ & $9,76 \mathrm{E}-07$ \\
\hline Pattern recognition receptor signaling pathway (GO:0002221) & 138 & 89 & $3,75 E+04$ & $1,97 \mathrm{E}-06$ \\
\hline Toll-like receptor signaling pathway (GO:0002224) & 120 & 80 & $3,26 \mathrm{E}+04$ & $5,80 \mathrm{E}-06$ \\
\hline Toll-like receptor 3 signaling pathway (GO:0034138) & 79 & 57 & $2,15 E+04$ & $5,06 \mathrm{E}-04$ \\
\hline Toll-like receptor 4 signaling pathway (GO:0034142) & 95 & 63 & $2,58 \mathrm{E}+04$ & $1,52 \mathrm{E}-03$ \\
\hline Toll-like receptor 9 signaling pathway (GO:0034162) & 73 & 52 & $1,99 \mathrm{E}+04$ & $4,80 \mathrm{E}-03$ \\
\hline TRIF-dependent toll-like receptor signaling pathway (GO:0035666) & 76 & 54 & $2,07 E+04$ & $2,56 \mathrm{E}-03$ \\
\hline Cellular response to cytokine stimulus (GO:0071345) & 457 & 218 & $1,24 \mathrm{E}+05$ & $3,25 \mathrm{E}-08$ \\
\hline Cytokine-mediated signaling pathway (GO:0019221) & 339 & 169 & $9,22 \mathrm{E}+04$ & $1,08 \mathrm{E}-06$ \\
\hline Regulation of type I interferon production (GO:0032479) & 106 & 78 & $2,88 \mathrm{E}+04$ & $9,02 \mathrm{E}-08$ \\
\hline Positive regulation of type I interferon production (GO:0032481) & 75 & 56 & $2,04 \mathrm{E}+04$ & 2,13E-04 \\
\hline
\end{tabular}

Viral uptake experiments performed with IFN $\alpha$-treated BDCA1-positive tonsillar cells demonstrated a higher VLP capture capacity when compared to mock-treated BDCA1-positive cells (Figure 7G), and was specifically inhibited by pre-treatment with an anti-Siglec-1 mAb (Figure 7G). Of note, neither the BDCA1-negative cell population nor $\mathrm{B}$ cells, which express BDCA1 and could thus be present in the BDCA1-positive cell fraction, were able to up-regulate VLP uptake after IFN $\alpha$ treatment (Additional file 1: Figure S2). In order to investigate HIV-1 trafficking in IFN $\alpha$-treated BDCA1positive cells, we added fluorescent HIV-1 $1_{\text {Cherry }}$ for $4 \mathrm{~h}$ at $37^{\circ} \mathrm{C}$ and subsequently stained cells with an anti-Siglec-1 mAb (Figure 7H). Confocal microscopy indicated that most of these BDCA1-positive cells accumulated HIV-1 $1_{\text {Cherry }}$ within a sac-like compartment 
enriched in Siglec-1, as previously observed for DCs and monocytes (Figure 2C).

Finally, to work with highly purified cell populations, we sorted $\mathrm{BDCA} 1^{+} \mathrm{CD} 2^{-} \mathrm{CD} 20^{-}$-tonsillar cells cultured in the presence of IFN $\alpha$ and assessed Siglec-1 involvement in HIV-1 trans-infection. IFN $\alpha$-activated BDCA1positive cells pre-treated with isotype control or specific $\mathrm{mAb}$ were exposed to $\mathrm{HIV}-1$ for $4 \mathrm{~h}$ at $37^{\circ} \mathrm{C}$, extensively washed and co-cultured with a $\mathrm{CD} 4^{+}$reporter cell line for 2 days (Figure 7I). Trans-infection was readily observed and was specifically inhibited by pre-treatment with a mAb against Siglec-1 (Figure 7I). These results indicated that ex vivo, activation of myeloid cells from tonsils with IFNa leads to Siglec1-dependent enhanced HIV-1 capture and trans-infection, supporting a potential role of Siglec-1 as an important molecule that could contribute to viral capture and trans-infection within lymphoid tissues in HIV-1-infected individuals.

\section{Discussion}

In this report, we show that Siglec-1 on myeloid cells (i) is up-regulated by IFN $\alpha$; (ii) mediates HIV-1 capture and trans-infection; (iii) correlates in vivo with the levels of plasma viral load and diminishes after effective antiretroviral treatment, and (iv) is expressed in lymphoid tissues in an inflammation-dependent manner where it can mediate HIV-1 trans-infection. Taken together, these findings indicate that inflammatory processes or immune activating signals triggered by HIV-1 replication, such as IFN $\alpha$ release, stimulate Siglec-1 expression on myeloid cells, a process that could enhance viral capture and trans-infection of $\mathrm{CD}^{+}$target $\mathrm{T}$ cells within lymphoid tissues. Based on our results, this mechanism may be driven by IFN $\alpha$-activated monocytes and DCs, which exhibited higher Siglec-1 dependent trans-infection than macrophages. Yet, despite the faster viral degradation of captured virions in macrophages, Siglec-1 expression in this cell type may facilitate productive HIV-1 cis-infection [33].

This model is consistent with our findings that in vivo Siglec-1 expression is up-regulated on monocytes from HIV-1-infected individuals, but diminishes after effective antiretroviral treatment suppresses plasma viral load and virus-induced activating signals $[17,28]$. Our results are in line with previous reports showing Siglec-1 upregulation on circulating monocytes of HIV-1-infected individuals with higher plasma viral loads $[18,34]$. However, assays performed here provide functional evidence that monocytes isolated directly from HIV-1-infected individuals capture HIV-1 and trans-infect $\mathrm{CD}^{+}$target cells. We also found that Siglec-1 expression increased with plasma viral load and decreased with $\mathrm{CD}^{+}{ }^{+} \mathrm{T}$-cell counts in HIV-1 infected patients. Furthermore, stimuli present in the plasma of untreated HIV-1-infected individuals induced Siglec-1 expression on myeloid cells via type I IFN receptor signaling. Overall, these data suggest that Siglec-1 could become a useful biomarker to monitor chronic immune activation driven by HIV-1 infection.

Detection of Siglec-1 within lymphoid tissues suggests that this receptor could mediate HIV-1 capture and transmission in these compartments. Lymphoid tissues are the perfect scenarios to fuel novel infections, since they are major sites of HIV-1 replication [35], where plasmacytoid and myeloid cells accumulate during the course of HIV-1 infection [25,26] and IFNa is detected in lymph nodes of HIV-1-infected individuals [24]. Functional assays performed here with myeloid cells isolated from tonsils and activated with IFN $\alpha$ (to mimic the immune activation state driven by HIV-1 infection in the lymphoid tissues), identified Siglec-1 as a key receptor involved in viral capture and transmission.

\section{Conclusions}

We have shown that Siglec-1 expression on distinct primary myeloid cells can be induced during chronic HIV-1 infection in vivo and contribute to systemic viral dissemination. Our results strongly support that Siglec-1 is an important molecule that could accelerate HIV-1 transmission in the crowded cellular environment of lymphatic tissues, where many T-cells can contact myeloid cells. Future studies aimed at blocking Siglec-1 in adequate animal models will be required to shed light on the relative contribution of HIV-1 trans-infection to disease progression and might offer novel therapeutic approaches to halt HIV-1 cell-to-cell transmission.

\section{Methods}

\section{Ethics statement}

The institutional review board on biomedical research from Hospital Germans Trias i Pujol (HUGTIP) approved this study. All patients involved in this study gave their written informed consent to participate.

\section{Primary cells}

Peripheral blood mononuclear cells (PBMCs) were obtained from HIV-1-seronegative donors by Ficoll-Hypaque density gradient centrifugation and monocyte populations were isolated as described in [36]. Monocytes were differentiated into DCs with $1000 \mathrm{U} / \mathrm{ml}$ of granulocytemacrophage colony-stimulating factor plus $1000 \mathrm{U} / \mathrm{ml}$ of Interleukin-4 (both from R\&D). In parallel, monocytes from the same donors were differentiated into macrophages with $100 \mathrm{ng} / \mathrm{ml}$ of macrophage colony-stimulating factor (Preprotech). Cells were cultured for 7 days, and cytokines and media were replaced every two days. At day five, monocytes, DCs and macrophages were stimulated with 1000 $\mathrm{U} / \mathrm{ml}$ of Interferon-2 $\alpha$ (Sigma-Aldrich) for two days. 
HIV-1-infected individuals were selected from a cohort of patients with samples collected before and after antiretroviral treatment. Patient's characteristics are described in Table 1. HIV-1-negative males matched for age were included as healthy controls. To perform functional assays, PBMCs were thawed and monocytes were isolated with $\mathrm{CD}_{14}{ }^{+}$magnetic beads (Miltenyi Biotec). Of note, positive isolation did not up-regulate Siglec-1 expression.

Human tonsils were removed during tonsillectomies of individuals undergoing prescribed surgery at the HUGTIP. After mechanical disruption, mononuclear tonsillar cells were isolated by Ficoll-Hypaque gradient centrifugation. T- and B-lymphocytes were subsequently depleted with magnetic beads against $\mathrm{CD}^{+}$and $\mathrm{CD} 19^{+}$(Miltenyi Biotec) prior blocking of the Fc receptor (Miltenyi Biotec). Siglec-1 positive cells were sorted by isolating Siglec- $1^{+} / \mathrm{CD} 20^{-} / \mathrm{CD}^{-}$cells with mAbs7-239 $\alpha$-Siglec-1-PE (AbD Serotec), $\alpha$-CD2-PerCP and $\alpha$-CD20-PerCP (both from Becton Dickinson) in a FACSVantage SE after blocking Fc receptors with $1 \mathrm{mg} / \mathrm{ml}$ of human IgGs (hIgGs; Privigen, Behring CSL). Myeloid cells were also isolated either by $\mathrm{BDCA} 1$ positive selection with magnetic beads (Miltenyi Biotec) or by sorting $\mathrm{BDCA}^{+} / \mathrm{CD} 20^{-} / \mathrm{CD} 2^{-}$cells using $\mathrm{mAb} \alpha$-BDCA1-PE (Miltenyi Biotec), $\alpha$-CD2-PerCP and $\alpha$-CD20-PerCP. Cells were stimulated with 1000 $\mathrm{U} / \mathrm{ml} \mathrm{IFN \alpha}$ for $24-48 \mathrm{~h}$. Isolated cells were blocked with $1 \mathrm{mg} / \mathrm{ml}$ of hIgGs for $20 \mathrm{~min}$ at RT and stained with the following mAbs: $\alpha-C D 11 c-A P C-C y 7$ (BioLegend), $\alpha$-CCR7-PerCP (Biolegend), $\alpha$-Siglec-1-Alexa 488 (AbD Serotec), $\alpha$-HLA-DR-V450 (BD), $\alpha$-CD86FITC (BD), $\alpha$-BDCA1-PECy7 (Biolegend), $\alpha$-CD20PerCPCy5.5 (BD), $\alpha$-CD3-PerCP (BD) at $4^{\circ} \mathrm{C}$ for $30 \mathrm{~min}$. Samples were analyzed with LSRII using FlowJo software to evaluate collected data.

All primary cells were cultured in RPMI containing $10 \%$ fetal bovine serum (FBS), $100 \mathrm{U} / \mathrm{ml}$ of penicillin and $100 \mu \mathrm{g} / \mathrm{ml}$ of streptomycin (all from Invitrogen).

\section{Siglec-1 surface expression analysis by FACS}

$2 \times 10^{5}$ myeloid cells were blocked with $1 \mathrm{mg} / \mathrm{ml}$ of hIgGs and stained with mAb 7-239 $\alpha$-Siglec-1-PE or matched isotype-PE control (AbD Serotec) at $4^{\circ} \mathrm{C}$ for $30 \mathrm{~min}$. The mean number of Siglec-1 mAb binding sites per cell was obtained with a Quantibrite kit (Becton Dickinson) as previously described [9]. Samples were analyzed with FACSCalibur using CellQuest software to evaluate collected data.

Induction of Siglec-1 expression by plasmas of HIV-1negative individuals and HIV-1-infected individuals before or after successful antiretroviral treatment was assessed on $2 \times 10^{5}$ DCs derived from HIV-1-negative donors cultured for $24 \mathrm{~h}$ in the presence of $2 \%$ of each respective plasma. To block Siglec-1 induction by these plasmas, carrier-free recombinant $\mathrm{B} 18 \mathrm{R}$ protein (eBioscience) was added at $2 \mu \mathrm{g} / \mathrm{ml}$. DCs were labeled with mAb 7-239 $\alpha$-Siglec-1-PE and quantified by Quantibrite. Basal values of Siglec-1 in DCs non-exposed to plasma were subtracted for each sample.

\section{Plasmids, viral stocks and cell lines}

HEK-293 T and TZM-bl (obtained through the US National Institutes of Health [NIH] AIDS Research and Reference Reagent Program) were maintained in D-MEM containing $10 \%$ FBS, $100 \mathrm{U} / \mathrm{ml}$ of penicillin and $100 \mu \mathrm{g} / \mathrm{ml}$ of streptomicin.

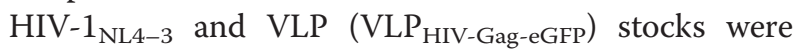
generated by transfecting the molecular clones pNL4-3 and pGag-eGFP obtained from the NIH AIDS Research and Reference Reagent Program. HIV $\mathrm{NL4-3-Cherry} \mathrm{was}$ obtained by cotransfection of pCHIV and pCHIVmCherry [37] (kindly provided by Dr. B. Muller). HEK$293 \mathrm{~T}$ cells were transfected with calcium phosphate (CalPhos, Clontech) in T75 flasks using $30 \mu$ g of plasmid DNA. Supernatants containing virus or VLPs were filtered (Millex HV, $0.45 \mu \mathrm{m}$; Millipore) and frozen at $-80^{\circ} \mathrm{C}$ until use. The $\mathrm{p} 24^{\mathrm{Gag}}$ content of the infectious viral stocks and VLPs was determined by an ELISA (Perkin-Elmer). HIV$1_{\mathrm{NL4}-3}$ used in infectious assays was titrated employing the TZM-bl reporter cell line that expresses luciferase under control of the HIV-1 promoter, as described in [38].

\section{VLP and HIV-1 binding and uptake assays}

Cells were pre-incubated at $4^{\circ} \mathrm{C}$ for $30 \mathrm{~min}$ with $10 \mu \mathrm{g} / \mathrm{ml}$ of the functional grade $\mathrm{mAb} \alpha$-Siglec-1 7-239, IgG1 isotype control (all from AbD Serotec) or left untreated. Binding was performed at $4{ }^{\circ} \mathrm{C}$ while uptake was done at $37^{\circ} \mathrm{C}$. To assess HIV- $1_{\mathrm{NL} 4-3}$ binding and uptake, $4 \times 10^{5}$ cells were pulsed with $970 \mathrm{ng}$ of p24 for $4 \mathrm{~h}$. After extensive washing, cells were lysed with $0.5 \%$ Triton X-100 to measure p24 ${ }^{\mathrm{Gag}}$ antigen content by an ELISA. To analyze viral degradation, cells were pre-incubated with $250 \mathrm{nM}$ of bafilomycin A1 (Sigma) during $30 \mathrm{~min}$ at $37^{\circ} \mathrm{C}$ and then exposed to HIV $_{\text {NL43 }}$ in the presence of the drug or left untreated. To determine VLP binding and uptake, $2 \times 10^{5}$ myeloid cells were pulsed with $10 \mathrm{ng}$ of VLPs for $3 \mathrm{~h}$ and analyzed by FACS.

\section{HIV-1 trans-infection assays}

Myeloid cells were treated and pulsed with $\mathrm{HIV}-1_{\mathrm{NL} 4-3}$ as described above. After extensive washing, cells were co-cultured with the reporter cell line TZM-bl at a ratio 1:1 or 5:1. Cells were assayed for luciferase activity $48 \mathrm{~h}$ later (BrightGlo luciferase system; Promega) in a Fluoroskan Ascent FL luminometer (Thermo Labsystems). Background values consisting of non-HIV-1 pulsed cocultures were measured for each experiment. Of note, we chose the X4-tropic virus NL4-3 and short period 
co-culture assays to avoid productive cis-infection of myeloid cells and focus on trans-infection.

\section{Confocal microscopy analysis}

$4 \times 10^{5}$ myeloid cells were pulsed with HIV-1 $1_{\text {Gag-Cherry }}$ for $4 \mathrm{~h}$ at $37^{\circ} \mathrm{C}$ as previously described [9]. After extensive washing, cells were fixed and permeabilized (Fix \& Perm; Invitrogen) and stained with mAbs $\alpha$-Siglec-1 7-239 Alexa 488 (AbD Serotec), $\alpha$-HLA-DR-Alexa 647 (Clone L243, Biolegend) and DAPI for $30 \mathrm{~min}$. Cells were cytospun into coverslips and analyzed with an Ultraview ERS Spinning Disk System (Perkin-Elmer) mounted on a Zeiss Axiovert $200 \mathrm{M}$ inverted microscope. Volocity software (Perkin-Elmer) was used to analyze microscopy images as in [13].

\section{Paraffinized tissues and immunoenzyme staining}

Paraffinized tonsils from HIV-1 non-infected individuals were provided by the tissue bank of the National Center for Tumor Diseases (Heidelberg, Germany) and approved by the ethics committee of Heidelberg University (approval No. 206/2005). Immunoenzyme staining of Siglec-1 were performed on $2-\mu \mathrm{m}$ paraffin sections of formalin-fixed tissues in principle as reported [39]. Antigen retrieval was achieved by steam cooking the slides in $10 \mathrm{mM}$ citrate buffer (pH 6.1, Dako) for $30 \mathrm{~min}$. 10\% Earle's balanced salt solution (EBSS, Sigma Aldrich) supplemented with $1 \%$ HEPES, $0.2 \%$ bovine serum albumin, and $0.1 \%$ saponin (all from Sigma) at pH 7.4 was used as washing and permeabilization buffer. Primary mAb dilutions with $\alpha$-Siglec-1 7D2 (Novus Biologicals) were also prepared in this buffer and incubated overnight at $4^{\circ} \mathrm{C}$. Slides were blocked in 15\% sheep serum for $20 \mathrm{~min}$ and revealed by biotinylated sheep anti-mouse $\mathrm{Ab}$ for $30 \mathrm{~min}$ at RT. Immunoenzyme staining was performed with standard avidin-biotin anti-alkaline phosphatase techniques (Vectastain). Naphthol AS-biphosphate (Sigma) with New Fuchsin (Merck) was used as the substrate for alkaline phosphatase. Slides were viewed with an Olympus BX45 microscope. Tonsils were classified by an experienced pathologist as inflamed based on strong tissue infiltration of neutrophil granulocytes.

Paraffinized axillary and abdominal lymph nodes from an $\mathrm{HIV} / \mathrm{HCV}$ co-infected patient were analyzed at the Pathology Department of HUGTIP. For immunohistochemistry, 4- $\mu \mathrm{m}$ paraffin-embedded sections were cut, deparaffinized and rehydrated through xylene and graded alcohols to water. Antigen retrieval was done immersing the slides for 40 minutes in EDTA Buffer in a water bath at $98^{\circ} \mathrm{C}$. The staining was performed using as primary mAbs $\alpha$-Siglec-1 7D2, $\alpha$-CD4 (Clone SP35, Ventana Medical Systems) and $\alpha$-CD20cy (Clone L26, DAKO) and the Ventana Discovery XT automated stainer (Ventana Medical Systems,) with ultraView
Universal DAB Detection Kit. Of note, patient had been treated with two nucleoside reverse transcriptase inhibitors for 7 years and had stopped treatment for 4 years, when the first biopsy was performed. At that time point, HIV-1 plasma viral load was $<50$ HIV-1 RNA copies/ml and $\mathrm{CD}^{+} \mathrm{T}$ cell-count was 485 . Patient started antiretroviral treatment again with a protease inhibitorbased regimen and had a second biopsy one year later, when HIV-1 plasma viral load was $<25$ HIV-1 RNA copies/ml and $\mathrm{CD}^{+}{ }^{+} \mathrm{T}$ cell-count was 511 . At the second biopsy, HCV viral load was 641.144 UI/ml.

\section{Transcriptome RNA-seq analysis}

RNA extraction from IFN $\alpha$-treated DCs, macrophages and monocytes cells $\left(1-6 \times 10^{6}\right)$ was performed using RNeasy Mini kit (Qiagen). RNA extraction from sorted IFN $\alpha$-treated Siglec-1 tonsillar cells was performed using RNeasy Micro kit (Qiagen). mRNA-Seq library preparation was done with TruSeq RNA sample prep kit, Illumina (starting with capture of polyA-containing transcripts), followed by cluster generation (TruSeq single-end cluster generation kit, Illumina) and highthroughput sequencing on Illumina HiSeq2000 at the Genomics Technology Facility, University of Lausanne. The 100 bp single-end reads obtained were cleaned before alignment as described in [40]. Cleaned reads were aligned to the human reference genome with STAR aligner [41] using the ensembl gene GRCh37 release 70 annotation file. The number of reads per gene was quantified with HTSeq-count v.0.6.1 [42] with parameters mode $=$ union and type $=$ exon. We obtained an average library size of 45072173 uniquely mapped reads. All downstream analyses were performed taking as gene expression values the $\log _{10}$ of the number of library sizenormalized reads per kilobase of exonic sequence. A pseudo-count of 1 was added previous to the $\log _{10}$ transformation to avoid NA's (impossible log transformation) and obtain a numerical value.

\section{Statistical analysis}

We analyzed mean changes using a paired t-test, which was considered significant at $P<0.05$. Mean changes of unpaired observations were assessed using the Man Whitney t-test, which was considered significant at $P<0.05$. Significant mean changes from $100 \%$ of the data normalized to percentages were assessed with a one sample t-test, considered significant at $P<0.04$. Pearson correlation tests were used to determine the level of association between Siglec-1 $\mathrm{Ab}$ binding sites per monocyte and VLP capture, HIV-1 capture, HIV-1 trans-infection, plasma viral load or CD4 ${ }^{+}$ T-cell counts from HIV-1-infected individuals. All analyses and figures were generated with the GraphPad Prism v5.0b Software. 


\section{Additional file}

Additional file 1: Figure S1. Siglec-1 mediates VLP capture by IFNatreated myeloid cells. A. Comparative binding of fluorescent VLPs to different myeloid cells previously exposed to IFNa. Cells were pulsed with VLPs for $3 \mathrm{~h}$ at $4^{\circ} \mathrm{C}$ and then assessed by FACS to measure the geometric mean fluorescence intensity (MFI). B. Relative binding of VLPs by different IFNa- treated myeloid cells pre-incubated with $10 \mu \mathrm{g} / \mathrm{ml}$ of the indicated mAbs. Values are normalized to the level of VLP bound by mock-treated cells (set at 100\%). C. Uptake of fluorescent VLPs by myeloid cells exposed to IFNa. Cells were pulsed with VLPs for $3 \mathrm{~h}$ at $37^{\circ} \mathrm{C}$ and assessed by FACS to measure the geometric MFI. D. Relative uptake of VLPS by IFNa-treated myeloid cells pre-incubated with $10 \mu \mathrm{g} / \mathrm{ml}$ of the indicated mAbs. Values are normalized to the level of VLP captured by mock-treated cells. All panels show mean values and SEM from 2 experiments including cells from 6 donors. Statistical differences were assessed with a paired t test in $A$, and with a one sample t-test in B and D. Figure S2. VLP uptake is not augmented in either tonsillar BDCA1-negative cells or B cells exposed to IFNa. A. Uptake of VLPs by CD19-/CD3-/BDCA1--tonsillar cells previously exposed to IFNa or left untreated. Cells were pre-incubated with $10 \mu \mathrm{g} / \mathrm{ml}$ of the indicated mAbs. Mean values and SEM from 2 experiments include cells from 5 donors. B. Uptake of VLPs by CD19+ tonsillar cells previously exposed to IFNa or left untreated. Cells were pre-incubated with $10 \mu \mathrm{g} / \mathrm{ml}$ of the indicated mAbs. Mean values and SEM include cells from 2 donors.

\section{Competing interests}

The authors declare that they have no competing interests.

\section{Authors' contributions}

Conceived and designed the experiments: MP JM-P NI-U. Performed the experiments: MP IE SB EE MT-F AR AC. Analyzed and interpreted the data: MP IE SB EE MT-F JD DO AR AC OK AT H-GK JM-P NI-U. Contributed vital materials: DG. Wrote the paper: MP H-GK JM-P NI-U. All authors read and approved the final manuscript.

\section{Authors' information}

Javier Martinez-Picado and Nuria Izquierdo-Useros share Dual Senior authorship.

\section{Acknowledgments}

For their excellent assistance and advice, we thank Elena Rebollo from the Advanced Fluorescence Microscopy Unit IBMB-PCB, Marco Fernández and Gerard Requena from the Flow Cytometer Unit of IGTP, Angela Fernández Vasalo from the Pathology Department of HUGTIP, the Sample Processing Team of IrsiCaixa, Elisabeth Gómez and Julià Blanco from IrsiCaixa and surgeons from the Otorhinolaryngology Department of HUGTIP. We are grateful to Barbara Mueller for providing key reagents and to Felix Lasitschka for expert histopathological assessment.

Work in JMP group is supported by the Spanish Ministry of Science and Innovation through grant SAF2013-49042-R, SAF2010-21224 and the Spanish AIDS network "Red Temática Cooperativa de Investigación en SIDA" (RD06/ 0006). NIU is supported by the Mathilde Krim Fellowship in basic biomedical research 108676 founded by "AmfAR" AIDS research Foundation. AC and AT are supported by the Swiss National Science Foundation. HGK is supported by the Deutsche Forschungsgemeinschaft through SFB/TR 83. The funders had no role in the design and preparation of this paper, decision to publish, or preparation of the manuscript.

\section{Author details}

${ }^{1}$ AIDS Research Institute IrsiCaixa, Institut d'Investigació en Ciències de la Salut Germans Trias i Pujol IGTP, Universitat Autònoma de Barcelona, Badalona, Spain. ${ }^{2}$ Institute of Medical Virology, National Reference Center for Retroviruses, University of Frankfurt, Frankfurt, Germany. ${ }^{3}$ Pathology Department, University Hospital Germans Trias i Pujol (HUGTIP), Badalona, Spain. ${ }^{4}$ Otorhinolaryngology Department, HUGTIP, Badalona, Spain. ${ }^{5}$ Institute of Microbiology, University Hospital Center and University of Lausanne, Lausanne, Switzerland. ${ }^{6}$ Swiss Institute of Bioinformatics (SIB) - Vital-IT, Lausanne, Switzerland. ${ }^{7}$ Current address: The J. Craig Venter Institute, La Jolla, CA, USA. ${ }^{8}$ Department of Infectious Diseases, Virology, Universitätsklinikum Heidelberg, Heidelberg, Germany. ${ }^{9}$ Institució Catalana de Recerca i Estudis Avançats ICREA,
Barcelona, Spain. ${ }^{10}$ University of Vic-Central University of Catalonia (UVic-UCC), Vic, Spain.

Received: 15 January 2015 Accepted: 24 March 2015

Published online: 07 May 2015

\section{References}

1. Sonza S, Maerz A, Deacon N, Meanger J, Mills J, Crowe S. Human immunodeficiency virus type 1 replication is blocked prior to reverse transcription and integration in freshly isolated peripheral blood monocytes. J Virol. 1996;70:3863-9.

2. Arfi $V$, Rivière $L$, Jarrosson-Wuillème $L$, Goujon $C$, Rigal $D$, Darlix $J$, et al. Characterization of the early steps of infection of primary blood monocytes by human immunodeficiency virus type 1. J Virol. 2008;82:6557-65.

3. Wu L, KewalRamani VN. Dendritic-cell interactions with HIV: infection and viral dissemination. Nat Rev Immunol. 2006;6:859-68.

4. Hrecka K, Hao C, Gierszewska M, Swanson SK, Kesik-Brodacka M, Srivastava S, et al. Vpx relieves inhibition of HIV-1 infection of macrophages mediated by the SAMHD1 protein. Nature. 2011;474:658-61.

5. Laguette N, Sobhian B, Casartelli N, Ringeard M, Chable-Bessia C, Ségéral E, et al. SAMHD1 is the dendritic- and myeloid-cell-specific HIV-1 restriction factor counteracted by Vpx. Nature. 2011;474:654-7.

6. Cameron PU, Freudenthal PS, Barker JM, Gezelter S, Inaba K, Steinman RM. Dendritic cells exposed to human immunodeficiency virus type-1 transmit a vigorous cytopathic infection to CD4+ T cells. Science. 1992;257:383-7.

7. Geijtenbeek TB, Kwon DS, Torensma R, van Vliet SJ, van Duijnhoven GC, Middel J, et al. DC-SIGN, a dendritic cell-specific HIV-1-binding protein that enhances trans-infection of T cells. Cell. 2000;100:587-97.

8. McDonald D, Wu L, Bohks SM, KewalRamani VN, Unutmaz D, Hope TJ. Recruitment of HIV and its receptors to dendritic cell-T cell junctions. Science. 2003;300:1295-7.

9. Izquierdo-Useros N, Lorizate M, Puertas MC, Rodriguez-Plata MT, Zangger $\mathrm{N}$, Erikson $\mathrm{E}$, et al. Siglec-1 is a novel dendritic cell receptor that mediates HIV-1 trans-infection through recognition of viral membrane gangliosides. PLoS Biol. 2012;10, e1001448.

10. Puryear WB, Akiyama H, Geer SD, Ramirez NP, Yu X, Reinhard BM, et al. Interferon-inducible mechanism of dendritic cell-mediated HIV-1 dissemination is dependent on Siglec-1/CD169. PLoS Pathog. 2013;9, e1003291.

11. Pulliam L, Sun B, Rempel H. Invasive chronic inflammatory monocyte phenotype in subjects with high HIV-1 viral load. J Neuroimmunol. 2004;157:93-8

12. Hartnell A, Steel J, Turley H, Jones M, Jackson DG, Crocker PR. Characterization of human sialoadhesin, a sialic acid binding receptor expressed by resident and inflammatory macrophage populations. Blood. 2001;97:288-96.

13. Izquierdo-Useros N, Lorizate M, Contreras F-X, Rodriguez-Plata MT, Glass B, Erkizia I, et al. Sialyllactose in viral membrane gangliosides is a novel molecular recognition pattern for mature dendritic cell capture of HIV-1. PLoS Biol. 2012;10, e1001315.

14. Puryear WB, Yu X, Ramirez NP, Reinhard BM, Gummuluru S. HIV-1 incorporation of host-cell-derived glycosphingolipid GM3 allows for capture by mature dendritic cells. Proc Natl Acad Sci U S A. 2012;109:7475-80.

15. Stacey AR, Norris PJ, Qin L, Haygreen EA, Taylor E, Heitman J, et al. Induction of a striking systemic cytokine cascade prior to peak viremia in acute human immunodeficiency virus type 1 infection, in contrast to more modest and delayed responses in acute hepatitis $B$ and $C$ virus infections. J Virol. 2009;83:3719-33.

16. Hazenberg MD, Otto SA, van Benthem BH, Roos MT, Coutinho RA, Lange $J M$, et al. Persistent immune activation in HIV-1 infection is associated with progression to AIDS. AIDS. 2003;17:1881-8.

17. Brenchley JM, Price DA, Schacker TW, Asher TE, Silvestri G, Rao S, et al. Microbial translocation is a cause of systemic immune activation in chronic HIV infection. Nat Med. 2006;12:1365-71.

18. Rempel H, Calosing C, Sun B, Pulliam L. Sialoadhesin expressed on IFN-induced monocytes binds HIV-1 and enhances infectivity. PLoS One. 2008;3, e1967.

19. von Sydow M, Sönnerborg A, Gaines H, Strannegård O. Interferon-alpha and tumor necrosis factor-alpha in serum of patients in various stages of HIV-1 infection. AIDS Res Hum Retroviruses. 1991;7:375-80.

20. Mandl JN, Barry AP, Vanderford TH, Kozyr N, Chavan R, Klucking S, et al. Divergent TLR7 and TLR9 signaling and type I interferon production 
distinguish pathogenic and nonpathogenic AIDS virus infections. Nat Med. 2008;14:1077-87.

21. Yonezawa A, Morita R, Takaori-Kondo A, Kadowaki N, Kitawaki T, Hori T, et al. Natural alpha interferon-producing cells respond to human immunodeficiency virus type 1 with alpha interferon production and maturation into dendritic cells. J Virol. 2003;77:3777-84.

22. Beignon AS, McKenna K, Skoberne M, Manches O, DaSilva I, Kavanagh DG, et al. Endocytosis of HIV-1 activates plasmacytoid dendritic cells via Toll-like receptor-viral RNA interactions. J Clin Invest. 2005;115:3265-75.

23. Kader M, Smith AP, Guiducci C, Wonderlich ER, Normolle D, Watkins SC, et al. Blocking TLR7- and TLR9-mediated IFN-a production by plasmacytoid dendritic cells does not diminish immune activation in early SIV infection. PLoS Pathog. 2013;9, e1003530.

24. Nascimbeni M, Perié L, Chorro L, Diocou S, Kreitmann L, Louis S, et al. Plasmacytoid dendritic cells accumulate in spleens from chronically HIV-infected patients but barely participate in interferon-alpha expression. Blood. 2009;113:6112-9.

25. Dillon SM, Robertson KB, Pan SC, Mawhinney S, Meditz AL, Folkvord JM, et al. Plasmacytoid and myeloid dendritic cells with a partial activation phenotype accumulate in lymphoid tissue during asymptomatic chronic HIV-1 infection. J Acquir Immune Defic Syndr. 2008;48:1-12.

26. Lore K, Sonnerborg A, Brostrom C, Goh LE, Perrin L, McDade H, et al. Accumulation of DC-SIGN + CD40+ dendritic cells with reduced CD80 and CD86 expression in lymphoid tissue during acute HIV-1 infection. AIDS 2002;16:683-92.

27. Miller MJ, Safrina O, Parker I, Cahalan MD. Imaging the single cell dynamics of CD4+ T cell activation by dendritic cells in lymph nodes. J Exp Med. 2004;200:847-56.

28. Stylianou E, Aukrust P, Bendtzen K, Müller F, Frøland SS. Interferons and interferon (IFN)-inducible protein 10 during highly active anti-retroviral therapy (HAART)-possible immunosuppressive role of IFN-alpha in HIV infection. Clin Exp Immunol. 2000;119:479-85.

29. Popovic M, Tenner-Racz K, Pelser C, Stellbrink HJ, van Lunzen J, Lewis G, et al. Persistence of HIV-1 structural proteins and glycoproteins in lymph nodes of patients under highly active antiretroviral therapy. Proc Natl Acad Sci U S A. 2005:102:14807-12.

30. Fletcher V, Staskus K, Wietgrefe W, Rothenberger M, Reilly C, Chipman G, et al. Persistent HIV-1 replication is associated with lower antiretroviral drug concentrations in lymphatic tissues. Proc Natl Acad Sci U S A. 2014;111:2307-12.

31. Guilliams M, Ginhoux F, Jakubzick C, Naik SH, Onai N, Schraml BU, et al. Dendritic cells, monocytes and macrophages: a unified nomenclature based on ontogeny. Nat Rev Immunol. 2014;14:571-8.

32. Segura E, Touzot M, Bohineust A, Cappuccio A, Chiocchia G, Hosmalin A, et al. Human inflammatory dendritic cells induce Th17 cell differentiation. Immunity. 2013;38:336-48.

33. Zou Z, Chastain A, Moir S, Ford J, Trandem K, Martinelli E, et al. Siglecs facilitate HIV-1 infection of macrophages through adhesion with viral sialic acids. PLoS One. 2011;6, e24559.

34. van der Kuyl AC, van den Burg R, Zorgdrager F, Groot F, Berkhout B, Cornelissen M. Sialoadhesin (CD169) expression in CD14+ cells is upregulated early after HIV-1 infection and increases during disease progression. PLoS One. 2007;2, e257.

35. Haase AT, Henry K, Zupancic M, Sedgewick G, Faust RA, Melroe H, et al. Quantitative image analysis of HIV-1 infection in lymphoid tissue. Science. 1996;274:985-9.

36. Izquierdo-Useros N, Blanco J, Erkizia I, Fernández-Figueras MT, Borràs FE, Naranjo-Gómez M, et al. Maturation of blood-derived dendritic cells enhances human immunodeficiency virus type 1 capture and transmission. J Virol. 2007:81:7559-70.

37. Lampe M, Briggs JA, Endress T, Glass B, Riegelsberger S, Kräusslich HG, et al. Double-labelled HIV-1 particles for study of virus-cell interaction. Virology. 2007;360:92-104

38. Li M, Gao F, Mascola JR, Stamatatos L, Polonis VR, Koutsoukos M, et al. Human immunodeficiency virus type 1 env clones from acute and early subtype B infections for standardized assessments of vaccine-elicited neutralizing antibodies. J Virol. 2005;79:10108-25.

39. Erikson E, Adam T, Schmidt S, Lehmann-Koch J, Over B, Goffinet C, et al. In vivo expression profile of the antiviral restriction factor and tumor-targeting antigen CD317/BST-2/HM1.24/tetherin in humans. Proc Natl Acad Sci U S A. 2011;108:13688-93.
40. Mohammadi P, di lulio J, Muñoz M, Martinez R, Bartha I, Cavassini M, et al. Dynamics of HIV latency and reactivation in a primary CD4+ T cell model. PLoS Pathog. 2014;10, e1004156.

41. Dobin A, Davis CA, Schlesinger F, Drenkow J, Zaleski C, Jha S, et al. STAR: ultrafast universal RNA-seq aligner. Bioinformatics. 2013;29:15-21.

42. Anders S, Pyl PT, Huber W. HTSeq-A Python framework to work with high-throughput sequencing data. Bioinformatics. 2014;31:166-9.

\section{Submit your next manuscript to BioMed Central and take full advantage of:}

- Convenient online submission

- Thorough peer review

- No space constraints or color figure charges

- Immediate publication on acceptance

- Inclusion in PubMed, CAS, Scopus and Google Scholar

- Research which is freely available for redistribution 